\title{
Influence of Intestinal Strangulation Release on Ischemia- reperfusion Injury in Sprague Dawley Rats
}

\author{
Ahmad Yani, ${ }^{1}$ Dorothy Dorothy, ${ }^{2}$ Rizky Amaliah ${ }^{1}$ \\ ${ }^{1}$ Department of Surgery, Faculty of Medicine, Universitas Indonesia, Dr. Cipto Mangunkusumo General \\ Hospital, Jakarta, Indonesia \\ ${ }^{2}$ Department of Surgery, Faculty of Medicine, Universitas Indonesia, Jakarta, Indonesia
}

Correspondence to: Dr. Dorothy Dorothy; email: dorothy.md@gmail.com

Received: 9 March 2020; Revised: 31 July 2020; Accepted: 7 September 2020; Available online: 2 November 2020

\begin{abstract}
Background: In intestinal ischemia, reperfusion towards the injured intestine can cause further injury to the intestine itself and to remote organs. This research aimed to evaluate the influence of intestinal strangulation release (SR) before resection on the intestine outside margin of the strangulated intestine compared with subjects without intestinal strangulation release (WSR). Methods: Fourteen male Sprague Dawley rats were subjected to strangulation of one loop of the distal ileum for $4 \mathrm{~h}$. In the SR group, the strangulated intestine was released for $5 \mathrm{~min}$ and then resected for necrotic parts. In the WSR group, the strangulated intestine was immediately resected WSR. The control group received a sham laparotomy. Four hours after the second laparotomy, the animals were sacrificed, and intestinal samples were taken for histomorphological analysis and measurement of intestinal
\end{abstract}

malondialdehyde (MDA) level. Results: The injury on the histomorphological intestinal mucosa and intestinal MDA level were insignificantly higher in the SR group than in the WSR group $(p>0.05)$. Conclusion: Intestinal SR before resection causes more tissue injury and oxidative stress on the intestine outside the strangulation section, but the difference is not statistically significant.

Keywords: Ischemia-reperfusion injury, Intestinal ischemia, Intestinal strangulation release, Malondialdehyde, Intestine injury

Ann Afr Surg. 2021; 18(2): 90-95

DOI: http://dx.doi.org/10.4314/aas.v18i2.6

Conflicts of Interest: None

Funding: None

(C) 2021 Author. This work is licensed under the Creative Commons Attribution 4.0 International License.

\section{Introduction}

Intestinal strangulation is one of the most common surgical cases that can interfere with the flow of blood vessels to the intestine, as in the case of hernia, volvulus, and intussusception, which also causes half of all cases of death involving small intestine obstruction $(1,2)$. Intestinal strangulation along with its complications has a morbidity rate of $40 \%$ (3). Ischemia-reperfusion (I/R) injuries can affect many organs, but the intestine is one of the organs most susceptible to this condition (4).
Disorders of blood flow to the intestine can cause ischemic injury, which causes tissue injury, but a more complicated condition can happen when blood flow is restored to the previously ischemic tissue to maintain cell function, known as reperfusion injury. Injuries due to reperfusion often outweigh injuries caused by the previous ischemia $(1,4,5)$.

When the ischemic condition occurs, hypoxanthine, a byproduct of adenosine triphosphate, accumulates. 
When tissue reperfusion occurs, hypoxanthine and oxygen produce a superoxide which causes inflammatory responses and tissue injury $(1,6)$. In intestinal ischemia with clear boundaries, a release is often performed to assess doubtful intestinal viability. However, the act of strangulation release (SR) can cause reperfusion injury, which may be prevented by resecting all the strangulated part without releasing the strangulation. Knowledge of the effects of intestinal SR is expected to be a consideration for deciding whether SR should be carried out before resecting the ischemic intestine. The best parameters for assessing intestinal injury without clinical signs are histopathological examination and malondialdehyde (MDA) levels.

This research aimed to determine differences in intestinal histomorphological changes and intestinal MDA levels in locations adjacent to strangulation, between intestines that are resected with and without previous SR.

\section{Material and methods \\ Animals}

This research was experimental and used male Sprague Dawley rats. The subjects selected were of male sex, healthy, aged between 8 and 12 weeks, with a median bodyweight (BW) of 183.50 (174-213) g. The subjects were received and raised in Pusat Penelitian dan Pengembangan Kesehatan (Puslitbang), Health Research and Development Agency, Ministry of Health of the Republic of Indonesia. This research was approved by the Ethics Committee of Penelitian Kesehatan Fakultas Kedokteran Universitas Indonesia No. 0554/UN2.F1/ETIK/2018 and followed the ethical guidelines for animal research. The sample size in this research was calculated using Federer's formula approach and considered a $10 \%$ dropout correction.

The subjects were given ad libitum food and drink before treatments, their general condition was assessed, and they were weighed to get animals of the same sample size. The subjects were raised in plastic cages 50 $\times 35 \times 15 \mathrm{~cm}$ with a battery system base. The cages were kept at room temperature, with indirect sunlight at the same cycle as in nature.

\section{Experimental procedures}

This research included 14 subjects: 2 rats in the control group, 6 rats in the group that received resection after $\mathrm{SR}$, and 6 rats in the group that received WSR.

At the time of the experiment, the subjects were anesthetized with a $50 \mathrm{mg} / \mathrm{kg} \mathrm{BW}$ dose of ketamine and $7 \mathrm{mg} / \mathrm{kg}$ BW dose of xylazine by intramuscular injection.

A median laparotomy incision of $3 \mathrm{~cm}$ was performed along the abdomen. In the two treatment groups, a 10$\mathrm{cm}$ length loop of distal ileum was strangulated using a 2.0 silk ligation, and then the abdomen was closed.

The distal ileum was chosen in this study as it is considered one of the commonest locations of strangulations, especially those caused by intussusception (7). Specifically, in the small intestine, reperfusion after ischemia initiates systemic inflammatory responses which lead to cell and tissue injuries (8). Hence, I/R injury in the small intestine is considered an important clinical problem leading to high mortality and morbidity. The total length of small intestine observed in a subject in this study was $100 \mathrm{~cm}$. This was approximated from a previous study which stated that a rat weighing $125 \mathrm{~g}$ has a $95-\mathrm{cm}$ long small intestine, which increases by approximately $5 \mathrm{~cm}$ for each $100 \mathrm{~g}$ of BW increment (9). Hence, the ratio of strangulated gut versus total gut length in this study was $1: 10$.

Ligation was released after $4 \mathrm{~h}$ of strangulation. Reperfusion duration was determined to be $15 \mathrm{~min}$. This reperfusion time was chosen to resemble the reality of a clinical setting where $15 \mathrm{~min}$ is the maximum time allocated to evaluate the intestine's viability. Thereafter the necrotic intestine was resected after evaluating the intestinal viability in the SR group, and the abdomen was closed. Meanwhile, in the WSR group, the ischemic intestine was resected without releasing the ligation.

Four hours later, two intestinal samples from each rat were taken using a surgical procedure. All SR samples (sample I) were fixed in $10 \%$ formalin buffer for histomorphological examination. All WSR samples (sample II) were put into containers that contained $0.9 \%$ sodium chloride $(\mathrm{NaCl})$ and stored at $20^{\circ} \mathrm{C}$ to measure tissue MDA level. The subjects were then sacrificed by 
YANI ET AL.

extracting all the blood directly from their hearts. MDA is used as an indicator because MDA is the final product of oxidative decomposition, which is initiated by radicals from polyunsaturated fatty acids $(10,11)$.

\section{Histopathological examination of the intestine}

A paraffin block was made from sample I; it was cut into $4-\mu \mathrm{m}$ thick slices and stained with hematoxylin and eosin. All histomorphological examinations were observed blindly by a pathologist. Mucosal lesions were classified by a scale of 0 to 5 , as described by Chiu et al. (12) (Table 1).

\section{Malondialdehyde examination of intestinal tissue}

A thiobarbituric acid (TBA) reaction was used to produce an MDA-TBA adduct. MDA measurement results were listed in $\mathrm{nmol} / \mathrm{mL}$ using an MDA assay kit by Abcam Manufacturer, Cambridge, USA.

\section{Statistical analysis}

The degree of intestinal mucosal injury and intestinal MDA levels was presented as numerical data. A Shapiro-Wilk test tested the normality of numerical data. The Kruskal-Wallis test was used for abnormal distribution numerical data. A one-way analysis of variance (ANOVA) test was used for normal distribution numerical data. Statistically significant differences were obtained if $p<0.05$.

\section{Results}

Fourteen male, healthy Sprague Dawley rats were divided into three groups. No significantly different BW and tissue sample weights were found between the control, SR and WSR groups. Table 2 shows the complete data of BW and tissue weight between control and treatment groups.

Table 3 shows a comparison of the histomorphological intestinal mucosal injury grade of each group. In the analysis, differences were insignificant in intestinal mucosal injury grade between the control, SR and WSR groups. Figure 1 shows histology images of intestinal mucosal injury.
In the analysis of MDA levels in the control group, SR, and WSR treatments using the one-way ANOVA parametric test for intestinal MDA, the MDA levels between groups showed a result of $\mathrm{p}>0.05$.

Table 3 shows the complete data.

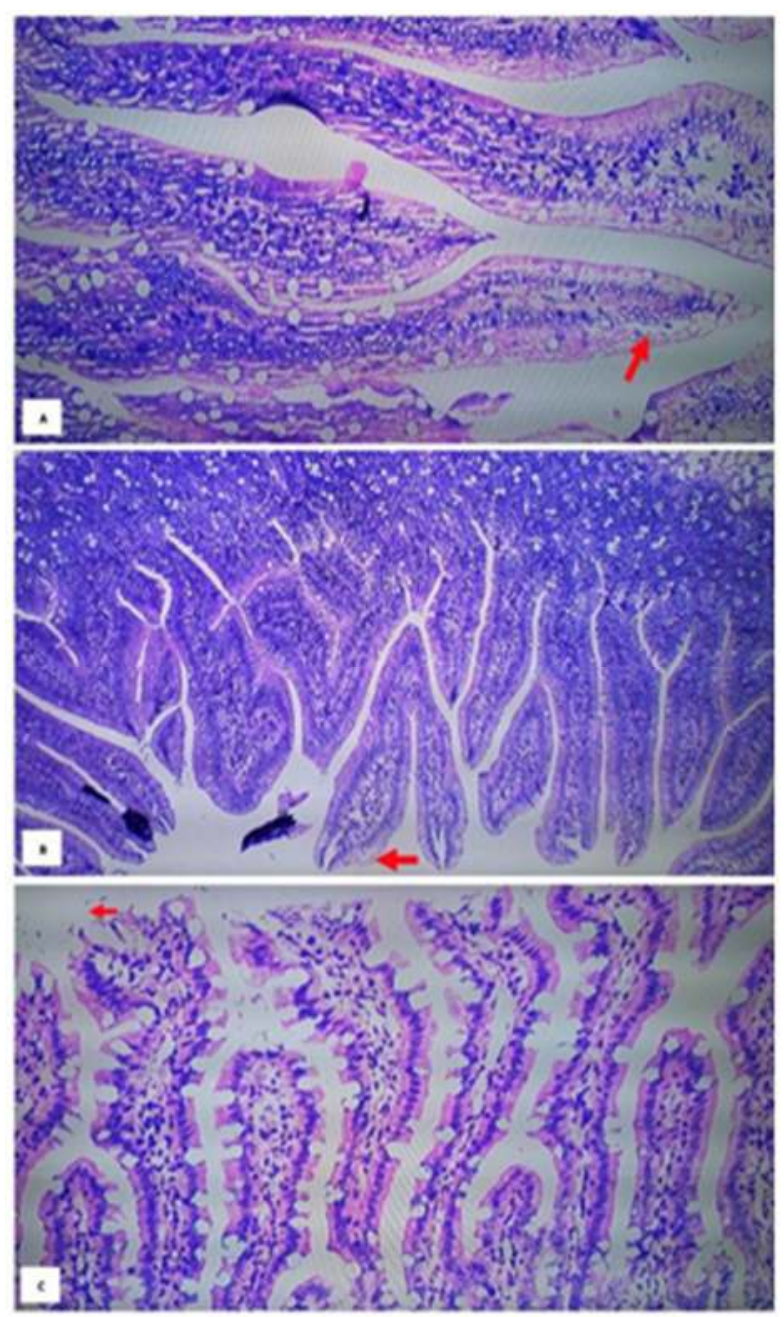

Figure 1. Histology images of intestinal mucosal injury

\section{Discussion}

In this research, intestinal injury increased but the difference was insignificant. The model of strangulation used in this study was a $10-\mathrm{cm}$ length loop of distal ileum. This ileal loop was considered as having the potential to induce a partial critical intestinal ischemia,

Table 1. Histopathological grading criteria for intestinal mucosal injury 


\begin{tabular}{ll}
\hline Grade & Histopathological findings \\
\hline 0 & $\begin{array}{l}\text { Normal mucosal villi } \\
\text { Development of subepithelial Gruenhagen's space, usually at the apex of the villus; often with } \\
\text { capillary congestion }\end{array}$ \\
2 & $\begin{array}{l}\text { Extension of the subepithelial space with the moderate lifting of epithelial layer from the lamina } \\
\text { propria }\end{array}$ \\
3 & Massive epithelial lifting down the sides of the villi. A few tips may be denuded \\
4 & Denuded villi with lamina propria and dilated capillaries exposed \\
5 & Increased cellularity of lamina propria may be noted \\
6 & Digestion and disintegration of lamina propria; hemorrhage and ulceration \\
\hline
\end{tabular}

Table 2. Comparison of BW and tissue weight between the control group, SR group and WSR group

\begin{tabular}{lllll}
\hline Variable & Control & SR & WSR & $\mathrm{p}$ \\
\hline BW $(\mathrm{g})$ & $186.50(185-188)$ & $184.00(176-213)$ & $182.00(174-193)$ & $0.789^{*}$ \\
Small intestine $(\mathrm{mg})$ & $103.45 \pm 2.05$ & $104.83 \pm 4.47$ & $102.45 \pm 1.22$ & $0.456^{* *}$ \\
\hline
\end{tabular}

*Kruskal-Wallis test **One-way ANOVA test.

BW: body weight; SR: strangulation release; WSR: without strangulation release.

Table 3. Comparison of intestinal mucosal injury scoring and intestinal MDA levels in the control group, the SR group and the without strangulation release WSR group

\begin{tabular}{lllll}
\hline & Control & SR & WSR & $p$ \\
\hline $\begin{array}{l}\text { Scoring of intestinal } \\
\text { mucosal injury }\end{array}$ & $0.5(0-1)$ & $1.5(0-3)$ & $0.5(0-1)$ & 0.078 \\
$\begin{array}{l}\text { Intestinal MDA level } \\
(\mathrm{nmol} / \mathrm{mL})\end{array}$ & $1.15 \pm 0.41$ & $1.30 \pm 0.43$ & $1.26 \pm 0.46$ & $0.915^{*}$ \\
\hline
\end{tabular}

*one-way ANOVA

MDA: malondialdehyde; SR: strangulation release; WSR: without strangulation release

compared with occlusion of cranial mesenteric artery as a global critical intestinal ischemia (13).

Moreover, this insignificant result might be due to the small sample size, which is a weakness of this study. A previous study by Yamamoto et al. (14) showed macroscopic findings in the intestine of Wistar rats that underwent reperfusion using a superior mesenteric artery clamp model. The intestine turned pale during the ischemic period but worsened after reperfusion and became cyanotic, in addition to a parenchymal hemorrhage. Microscopic findings of the intestine showed mucosal injury including denudation of the mucosa, and neutrophil infiltration into the injured mucosal layer that happens during the ischemia period but is exacerbated after reperfusion.

Another study by Guan et al. using a remote-controlled inflatable occluder of mouse jejunum and periintestinal marginal artery occluder, for long-term ischemia, resulted in irreversible epithelial cell structure and function (15). Research by Parks and Granger showed that mucosal injuries that occur after 3 $\mathrm{h}$ of ischemia followed by $1 \mathrm{~h}$ of reperfusion are greater than mucosal injuries produced after $4 \mathrm{~h}$ of ischemia without reperfusion (16). Research by Caty et al., using Sprague Dawley rats as a model of intestinal $I / R$, showed increased levels of histamine, xanthine oxidase and xanthine dehydrogenase in ischemia for $120 \mathrm{~min}$ and reperfusion for $15 \mathrm{~min}$. The xanthine oxidase activity which was measured after $15 \mathrm{~min}$ of reperfusion had increased by as much as $140 \%$ more than xanthine oxidase activity of $120 \mathrm{~min}$ for ischemia alone (17). These results show that intestinal mucosal injury is more severe due to the action of reperfusion of the intestine itself rather than during the ischemic period (16).

$\mathrm{I} / \mathrm{R}$ injury not only injures the local tissue but also causes a systemic inflammatory response. A study by Grosche et al. reported the activation of eosinophils, 
other leukocytes, and production of nitrogen radicals after ischemia and reperfusion in the colon of horses. These cells are potentially involved in the inflammatory response. The authors also reported apoptosis in the large colonic mucosa itself, which might be the prominent cause of cell death during ischemia and reperfusion (18). Intestinal mucosal injury of I/R results in a failure to maintain a mucosal barrier that leads to increased plasma endotoxin levels, which indicate bacterial translocation (16). I/R injury is also known to be one of the main causes of multiple organ failure $(19,20)$. Therefore, in cases of intestinal strangulation, where the segment of the intestine in question seems to be non-vital, the act of resecting the intestine WSR or reperfusion is first expected to prevent the reperfusion injuries that occur.

The intestine consists of unstable enterocytes which can be easily injured due to ischemia, this also makes the intestine highly susceptible to I/R injury $(5,18)$. Enterocytes located at the tip of the microvilli are more sensitive to the effects of ischemia than enterocytes located in the crypt. This sensitivity is due to their location at the end of the distribution of central arterioles and having relatively less collateral blood flow so that the partial pressure of oxygen in arterial blood $\left(\mathrm{PaO}_{2}\right)$ in the distal enterocytes is lower than in the crypt. Xanthine oxidase activity, which is the main source of free radicals, is found mainly in the intestinal mucosal lining with increased activity from the bottom of the villus to the tip. This is also one of the reasons for the increased sensitivity of the end of the villus to $\mathrm{I} / \mathrm{R}$ injuries than the bottom of the villus (21).

This research also showed an insignificant difference in intestinal MDA levels in intestine tissue outside the strangulation margin between all groups. This also might be due to the model of strangulation and the time of reperfusion differences. However, previous studies with different models showed significant results. Research by Akman et al. using Wistar rats showed that inserting ileum with stylets in the intussusception model for $4 \mathrm{~h}$ resulted in a significant increase in MDA levels (10). Zheng et al. in their research obtained intestinal MDA values of $1.01 \pm 0.11$ for Sprague Dawley control rats and MDA value of $2.30 \pm 0.19$ in rats treated with clamps on the superior mesenteric artery for $45 \mathrm{~min}$ and using reperfusion for $120 \mathrm{~min}$ (22). Nilsson et al. (23) showed that I/R injury occurs after $2-5$ min of intestinal reperfusion, which causes oxidant production immediately in the ischemic intestine. Oxidant production after reperfusion originally comes from the electron transport chain in the mitochondria, xanthine oxidase, metabolism, endothelial cells, prostaglandins and activated neutrophils (20).

\section{Conclusion}

This research shows that intestinal SR before resection causes more tissue injury and oxidative stress on the intestine outside the strangulation margin, but it is an insignificant difference. Hence, an intestinal resection without any release procedure is recommended on the strangulated intestine with a low chance of viability.

\section{Acknowledgment}

We thank all who have helped with this research.

\section{References}

1. Gonzalez LM, Moeser AJ, Blikslager AT. Animal models of ischemia reperfusion-induced intestinal injury: progress and promise for translational research. Am J Physiol Gastrointest Liver Physiol. 2015;308: G63-75.

2. Hayanga AJ, Bass-Wilkins K, Bulkley GB. Current management of small-bowel obstruction. Adv Surg. 2005; 39:1-33.

3. Shatila AH, Chamberlain BE, Webb WR. Current status of diagnosis and management of strangulation obstruction of the small bowel. Am J Surg. 1976;132(3):299-303.

4. Teke Z, Sacar M, Yenisey C, et al. Activated protein C attenuates intestinal mucosal injury after mesenteric ischemia/reperfusion. J Surg Res. 2008;149(2):219-30.

5. Mallick IH, Yang WX, Winslet MC, et al. Ischemiareperfusion injury of the intestine and protective strategies against injury. Dig Dis Sci. 2004;49(9):13591377.

6. Collard CD, Gelman S. Pathophysiology, clinical manifestations, and prevention of ischemia-reperfusion injury. Anesthesiology. 2001; 94:1133-1138.

7. Lissauer T. Pediatric emergencies: a practical guide to acute paediatrics. New York: Appleton-Century-Crofts; 1982. p. 103.

8. Watanabe T, Tanigawa T, Kobata A, et al. Toll-like receptor 2 mediates ischemia-reperfusion injury of the small intestine in adult mice. PLoS One. 2014;9(10):1-7. 
9. Miller DL. Rat small intestine: development, composition and effects of perfusion. Am J Dig Dis. 1971;16(3):24754.

10. Akman H, Somuncu S, Dikmen G, et al. Protective effect of selenium on intussusception-induced ischemia/ reperfusion intestinal oxidative injury in rats. Turk J Med Sci. 2010;40(3):391-397.

11. Ayala A, Muñoz MF, Argüelles S. Lipid peroxidation: Production, metabolism, and signaling mechanisms of malondialdehyde and 4-hydroxy-2-nonenal. Oxid Med Cell Longev. 2014; 2014:360438.

12. Chiu CJ, McArdle AH, Brown R, et al. Intestinal mucosal lesions in low-flow states. A morphological, hemodynamic, and metabolic reappraisal. Arch Surg. 1970;101(4):478.

13. Kozhura VL, Basarab DA, Timkina MI, et al. Reperfusion injury after critical intestinal ischemia and its correction with perfluorochemical emulsion "perftoran." World J Gastroenterol. 2005;11(45):7084-7090.

14. Yamamoto S, Tanabe M, Wakabayashi G, et al. The role of tumor necrosis factor- $\alpha$ and interleukin- $1 \beta$ in ischemiareperfusion injury of the rat small intestine. J Surg Res. 2001;99(1):134-141.

15. Guan Y, Worrell RT, Pritts TA, et al. Intestinal ischemiareperfusion injury: reversible and irreversible damage imaged in vivo. Am J Physiol Gastrointest Liver Physiol. 2009;297(1): G187-196.

16. Parks DA, Granger DN. Contribution of ischemia and reperfusion to mucosal lesion formation. Am J Physiol. 1986;250(6): G749-7453.

17. Caty MG, Schmeling DJ, Friedl HP, et al. Histamine: a promoter of xanthine oxidase activity in intestinal ischemia/reperfusion. J Ped Surg. 1990;25(2):218-223.

18. Grosche A, Vet M, Freeman DE, et al. On production of nitrotyrosine, activation of mucosa of horses. Am J Vet Res. 2012;73(1):53-61.

19. Watson MJ, Ke B, Shen XD, et al. Intestinal ischemia/reperfusion injury triggers activation of innate Toll-like receptor 4 and adaptive chemokine programs. Transplant Proc. 2008;40(10):3339-3341.

20. Cerqueira NF, Hussni CA, Yoshida WB. Pathophysiology of mesenteric ischemia/reperfusion: a review. Acta $\mathrm{Cir}$ Bras. 2005;20(4):336-343.

21. Sasaki M, Joh T. Oxidative stress in digestive disease. J Clin Biochem Nutr. 2007;40(1):1-12.

22. Zheng XF, Mao YF, Cai JM, et al. Hydrogen-rich saline protects against intestinal ischemia/reperfusion injury in rats. Free Radic Res. 2009;43(5):1-7.

23. Nilsson UA, Lundgren O, Haglind E, et al. Radical production during in vivo intestinal ischemia and reperfusion in the cat. Am J Physiol. 1989;257: G409-14. 